\title{
High Incidence of Pulmonary Tuberculosis in ART Naive Remunerated Blood Donors with Human Immunodeficiency Virus Type-1 Infection: Possible Role of Iron Overload
}

\author{
Debasish Chattopadhya ${ }^{1,2 *}$, Usha Baveja ${ }^{3}$ \\ ${ }^{1}$ Centre for AIDS and Related Diseases, National Centre for Disease Control 22-Sham Nath Marg, Delhi, India \\ ${ }^{2}$ Department of Microbiology, Faculty of Medicine and Health Sciences, SGT University, Gurgaon, India \\ ${ }^{3}$ Department of Pathology and Lab Medicine, Medanta the Medicity, Gurgaon, India \\ Email: *dchattopadhya27@gmail.com
}

How to cite this paper: Chattopadhya, D. and Baveja, U. (2018) High Incidence of Pulmonary Tuberculosis in ART Naive Remunerated Blood Donors with Human Immunodeficiency Virus Type-1 Infection: Possible Role of Iron Overload. Journal of Biosciences and Medicines, 6, 62-82. https://doi.org/10.4236/jbm.2018.62006

Received: December 28, 2017

Accepted: February 25, 2018

Published: February 28, 2018

Copyright (๑) 2018 by authors and Scientific Research Publishing Inc. This work is licensed under the Creative Commons Attribution International License (CC BY 4.0).

http://creativecommons.org/licenses/by/4.0/

(c) (i) Open Access

\begin{abstract}
Iron overload is reported to be associated with immune alterations and increased susceptibility to infections. HIV infection is characterized by progressive immunodeficiency leading to invasion by opportunistic pathogens. It was of interest to find out if disease course in HIV type- 1 infection could have any relation with alteration in body iron status among individuals with history of oral iron intake. A follow-up study of immunologic and virologic markers in relation to disease progression was undertaken on asymptomatic HIV-1 positive blood donors with history of oral iron intake (subgroup I) compared to those without such history (subgroup II). High serum iron was associated with elevated levels of $\mathrm{Th}_{2}$ category of cytokines, heightened immune activation, faster decline in $\mathrm{CD} 4+\mathrm{T}$ lymphocyte count and higher viral set point. Pulmonary tuberculosis (PT) was the most common AIDS related illness (ARI) $(>70 \%)$ recorded among subgroup I compared to non-PT category of ARI. Median ARI free duration (months) was shorter among those who developed PT compared to those developing non-PT category of ARI i.e. 30 $(95 \% \mathrm{CI}$ as 26,32$)$ versus $67(95 \% \mathrm{CI}$ as 60,71$)$ in subgroup I and $47(95 \% \mathrm{CI}$ as $42,49)$ versus $80(95 \% \mathrm{CI}$ as 72,87$)$ in subgroup II $(P<0.001$ for PT versus non-PT in both subgroups). Median survival duration (months) in the PT versus non-PT categories of ARI was 47 (95\% CI as 42,48$)$ versus 95 (95\% CI as 90,100$)$ in subgroup I and $71(95 \% \mathrm{CI}$ as 65,76$)$ versus 107 (95\% CI as $102,112)$ in subgroup II ( $P<0.001$ for PT versus non-PT in both subgroups). The present study indicates that body iron overload resulting from excess intake of iron may be associated with qualitative defects in cell mediated im-
\end{abstract}


munity at early stage of HIV-1 infection that may facilitate subsequent acquisition of pulmonary tuberculosis, shorter ARI free duration and reduced survival.

\section{Keywords}

Iron Overload, HIV-1, Cytokines, CD4 + T Lymphocyte, Pulmonary Tuberculosis

\section{Introduction}

Remunerated (professional) blood donors have been identified as a major risk group in India for Human Immunodeficiency Virus (HIV) type-1 infection [1] [2] [3]. In an earlier study from our laboratory majority of the professional donors infected with HIV Type-1 (HIV-1) revealed history of donating blood at high frequency at multiple centres [1]. Preliminary verbal interaction with these donors revealed consumption of self-judged quantity of iron tablets to be a prevalent practice among them as a compensatory attempt to maintain hemoglobin status at qualifying level despite frequent blood donation (unpublished observation). Considering that such practice of consumption of iron tablets by the donors was not based on any physiological consideration to the quantum of blood loss through donation, it was of interest to find out if any alteration in the serum iron status could be related to disease progression and survival of the HIV-1 infected blood donors.

There are relatively few reports from India on disease progression and survival pattern in HIV-1 infected cases [4] [5] [6] while to the best of our knowledge there is no report from this country on disease progression in relation to any nutritional alteration. Studies elsewhere on the relationship between nutritional status and survival of HIV-1 infected persons suffered from heterogeneity of study population in terms of age, sex, stage of illness and peripheral CD4 $+\mathrm{T}$ lymphocyte counts [7] [8] [9]. The present prospective study, carried out over fifteen years, describes the pattern of natural course of disease progression in a group of ART naive male professional blood donors with asymptomatic HIV-1 infection in relation to serum iron status, viral load, peripheral CD4 + T lymphocyte count, serum levels of cytokines and immune activation markers viz. Tumour Necrosis Factor Alfa (TNF- $\alpha$ ) and its two soluble receptors viz. TNF-R p55 and TNF-R p75 [10] [11] [12].

\section{Materials and Methods}

\subsection{Study Subjects and Characteristics}

The subjects in the study included a group of professional blood donors enrolled during a period prior to introduction of legal ban on remunerated blood donation in the country in 1996. An independent institutional review board approved the protocol of the study including ethical consideration. Between February 1992 
and January 1996, the professional blood donors screened to be seropositive for HIV-1 infection at various blood banks in the city of Delhi and adjoining cities of Northern India and confirmed to be seropositive for HIV-1 infection at AIDS Reference Center, National Centre for Disease Control (formerly National Institute of Communicable Diseases), Delhi were initially enrolled for the study. Serological diagnosis of HIV-1 infection was based on screening Enzyme Linked Immunosorbent Assay (ELISA) using differential HIV-1/HIV-2 serological test and confirmatory Western blot test as described earlier [1] [13]. A confidential interview was conducted after obtaining consent from each donor to record age, marital status, duration and frequency of blood donation (for preceding 1 year), HIV related risk behaviors viz. frequency of unprotected sex with heterosexual and/or homosexual partners per week as well as number of sex partners (for preceding 1 year) and any history of parenteral drug abuse or receipt of blood transfusion.

Information was collected from each donor regarding intake of any medication or dietary supplement on a regular basis. Since consumption of oral iron in the form of tablets and alcoholic drinks were the only two non-dietary items reported by many of the donors, further information was collected from the donors with positive history for these two intakes. Information was collected about the consumption of iron tablets regarding preparation and quantum of daily consumption during past 3 months. In case of any donor not consuming uniform quantity of iron tablets every day in the week, the daily average quantity of consumption was calculated on the basis of total number of tablets consumed in a week. History regarding consumption of alcoholic drinks was elicited from the donors in terms of sessions/week while no consideration was given to brand or quantity of alcoholic drink consumed per session.

\subsection{Investigations at Enrolment}

\subsubsection{Anthropometric Assessment}

Height $( \pm 0.1 \mathrm{~cm})$ and weight $( \pm 0.1 \mathrm{Kg})$ were measured using standard techniques and body mass index (BMI) was calculated by the formula weight $(\mathrm{Kg}) /$ height $\left(\mathrm{m}^{2}\right)[14]$.

\subsubsection{Laboratory Studies}

Fasting blood was collected and distributed as about $6 \mathrm{ml}$ in plain sterile tube to yield serum for estimation of levels of albumin, iron parameters, cytokines, cytokine receptors as well as detection of serological markers for Syphilis, Hepatitis B virus (HBV) and Hepatitis $\mathrm{C}$ virus (HCV) infections and about $2 \mathrm{ml}$ in ethylene-diamine-tetra-acetic acid (EDTA) for routine hemoglobin, peripheral CD4 + T lymphocyte count and plasma viral load assay.

Determination of hemoglobin as well as estimation of serum levels of albumin, iron, ferritin and transferrin saturation (TS) percentage were carried out by techniques as described earlier [15]. Serological diagnosis of Syphilis was based on by detection of anti-treponemal antibody test using commercial Treponema 
pallidum hemagglutination (TPHA) test (Fujirebio, Tokyo, Japan). HBV infection was detected employing commercial Enzyme linked Immunosorbent assay kits for three markers viz. hepatitis B surface antigen (HBsAg), antibody to Hepatitis B surface antigen (anti-HBs) and antibody to Hepatitis B core antigen (anti-HBc) while diagnosis of HCV infection was carried out employing the micro-ELISA kits (Abbott laboratories, North Chicago, IL, USA) for detection of anti-HCV antibodies [16].

Enumeration of peripheral CD4 + T lymphocyte count was carried out from EDTA treated blood using Fluorescein isothiocyanate (FITC) conjugated anti CD4 monoclonal antibody staining of mononuclear cells obtained by whole blood lysis method (Q prep, Coulter Diagnostic, Hialeah, FI) and reading by flow cytometer (EPICS profile version II, Coulter, Hialeah, Fl) as described earlier [17].

Quantification of HIV-1 RNA level was carried out in stored plasma (at $-70^{\circ} \mathrm{C}$ ) collected at enrolment employing commercial viral load assay (Amplicor HIV Monitor assay, version 1.5, Roche Molecular systems, Branchburg, NJ, USA) with sensitivity of 400 copies per $\mathrm{ml}$.

Levels of T helper type 1 (Th1) of cytokines viz. Interleukin-2 (IL-2) and gamma interferon (IFN- $\gamma$ ) and T helper type 2 (Th2) of cytokines viz. Interleukin-4 (IL-4) and Interleukin-10 (IL-10) were measured in serum using commercial reagents and ELISA kits (R \& D Systems, Minneapolis, MI, USA) with sensitivity limits of $7 \mathrm{pg} / \mathrm{ml}, 8 \mathrm{pg} / \mathrm{ml}, 10 \mathrm{pg} / \mathrm{ml}$ and $3.9 \mathrm{pg} / \mathrm{ml}$ for IL-2, IFN- $\gamma$, IL-4 and IL-10 respectively. Serum levels of TNF- $\alpha$, TNF- $\alpha$ receptor type I (TNFR p55) and type II (TNFR p75) were measured using commercial ELISA kits from same source as above with sensitivity levels of $5.5 \mathrm{pg} / \mathrm{ml}, 1.2 \mathrm{pg} / \mathrm{ml}$ and $2.3 \mathrm{pg} / \mathrm{ml}$ respectively. Inter assay coefficient of variation in all these assays were found to be less than $10 \%$. Readings below detection range were assigned zero values.

\subsubsection{Clinical Assessment}

The HIV-1 positive donors were referred to referral hospitals for clinical assessment to exclude cases suggestive of AIDS related illness (ARI) [18] and only cases identified as clinically asymptomatic were subjected to a panel of baseline biochemical investigations on fasting blood samples for routine liver, renal and thyroid function tests [19].

\subsubsection{Exclusion Criteria}

The following categories of HIV-1 positive donors were excluded from enrolment in the study in addition to those with inconsistent history regarding oral iron intake:

a) Any history of illness suggestive of ARI.

b) Peripheral CD $4+\mathrm{T}$ lymphocyte count $\leq 500$ cells/cu mm on any of three consecutive days samples.

c) Serological evidence of co-infection with HBV, HCV and Syphilis.

d) Abnormal values in liver, renal and thyroid function tests. 
e) Malignancy or any history of immunosuppressive therapy.

\subsection{Follow-Up Studies}

\subsubsection{Clinical Follow-Up}

All the HIV-1 positive blood donors enrolled in the present study were requested to report to the identified clinicians in referral hospitals if they developed any symptom regardless whether they were HIV-1 related or not. Information on the diagnosis of various ARIs was provided by the clinicians based on clinical findings, radiology and relevant laboratory investigations [20]. The ARIs were broadly grouped as pulmonary tuberculosis (PT) and ARIs other than pulmonary tuberculosis (non-PT category of ARI). The time of development of any ARI was recorded as the primary end point in the present study. In symptomatic cases reporting more than one of ARI specific symptoms, the symptom with longer duration was taken into consideration for the purpose of grouping of various ARIs. The donors, found surviving till the point of time when antiretroviral therapy (ART) program was introduced in the country (2005), were referred to ART designated centers as per national guidelines. Analysis of survival was undertaken in the HIV-1 positive donors by recording the time of AIDS related death among the ART naïve donors (secondary end point) excluding those enrolled for ART in order to avoid confounding effect of ART on calculation of survival duration [21]. Death was considered to be HIV related unless reported to be due to suicide, homicide, accident or clearly related to an underlying condition not included in WHO case definition for AIDS and if the last CD4 $+\mathrm{T}$ count before death indicated a count as $<50$ cells/cu mm [9] [21].

\subsubsection{Laboratory Follow-Up}

Peripheral CD4 + T lymphocyte count, viral load assay, serum levels of TNF- $\alpha$, TNF-R p55 and TNF-R p75 were repeated at 6 months, one year and at the time of development of any ARI for all the HIV-1 seropositive donors over a period of 16 years from the beginning of the study till the last donor in this group developed ARI. Serological markers of infections with HBV, HCV and Syphilis were also tested up to 6 months of post enrolment in order to eliminate cases with these co-infections at window phase at the time of enrolment. Thereafter, serological testing for HIV, HBV, HCV or Syphilis was carried out at 2 - 3 yearly intervals in order to exclude any donor demonstrating serological evidence of acquisition of these infections during the follow up period.

\subsection{Selection of Controls}

The following groups were included as controls taking into consideration the identical exclusion criteria employed for HIV-1 positive donors:

i) A group of $80 \mathrm{HIV}$ negative professional blood donors matched in terms of age, sex and marital status and donating at the same blood banks as that of HIV-1 positive donors (blood donor controls).

ii) A total of 40 healthy individuals from local community without any HIV 
related risk behavior, matched with the donor groups in terms of age, sex and socio-economic status and not in the profession of blood donation (community controls).

\subsection{Statistical Analysis [22]}

Statistical analysis was carried out employing SPSS package version 20.

The HIV-1 positive blood donors were sub-divided into two subgroups based on positive or negative history of oral iron consumption (subgroups I and II). The HIV negative donors were similarly grouped as those with or without positive history of oral iron consumption (subgroups III and IV). Non-donor community controls were assigned as subgroup V. The subgroups of HIV-1 positive and HIV negative donors were stratified based on frequency of blood donation into three categories viz. 6 weeks or less, more than 6 weeks to less than 3 months and equal to or more than 3 months.

Characteristics of blood donors viz. demographic, anthropometric and laboratory parameters as assessed at baseline were compared using $\chi^{2}$ test for categorical variables and student's t-test or one way ANOVA followed by post-hoc test with Bonferroni adjustment for continuous variables with normal distribution characteristics. Continuous variables not following normal distribution were compared by Kruskal Wallis test followed by multiple comparisons using Mann Whitney test with Bonferroni adjustment. $\mathrm{P}$ value $<0.05$ was considered as statistically significant and it was adjusted for multiple comparisons. Fisher's exact test was used if any of the expected cell frequency was less than five.

The HIV-1 positive donors who were not available for any follow up following initial enrolment were excluded for calculation of symptom free duration while any donor about whom no definite information about death was available was excluded from analysis of survival duration. Cumulative ARI free survival and overall survival were estimated by Kaplan-Meier methods with using log-rank $\chi^{2}$ test. Correlations between continuous variables were calculated by Pearson's correlation coefficient.

\section{Results}

Out of a total of $118 \mathrm{HIV}-1$ positive donors enrolled in the study, 60 (50.8\%) revealed the history of oral iron intake (subgroup I) and 58 (49.2\%) revealed negative history for such intake (subgroup II) while out of 80 HIV negative donors, a total of $30(37.5 \%)$ and 50 (62.5\%) donors revealed positive and negative history respectively for iron consumption (subgroups III and IV).

\subsection{Characteristics of Donors at Enrolment: Demography, Donation Frequency, HIV Related Risk Behaviours, Alcohol Intake and Nutritional Features}

All donors enrolled in the study were males, unmarried, belonging to the age group of 24 - 32 years (mean \pm SD as $27 \pm 2$ ). Regardless of HIV positivity most of donors with positive history of oral iron intake (subgroups I and III) were 
characterized by practice of donating blood at frequency higher than the recommended interval, majority donating at frequency of once at interval of 6 weeks or less. None of the donors in the present study gave history of parenteral drug abuse, receipt of blood transfusion or any other HIV related risk behavior except visit to female commercial sex workers (CSWs). There was no difference in the degree of high-risk behavior in terms of proportion of donors with positive history, frequency of unprotected sex or number of sex partners between the two subgroups of HIV-1 positive donors (i.e. subgroups I and II). Among the HIV negative donors, the subgroup III revealed higher degree of such high-risk behaviors compared to the subgroup IV donors. On the other hand, in both HIV-1 positive and HIV negative groups, proportion of donors with positive history of alcohol intake as well as weekly frequency of alcohol intake sessions were more in the subgroups consuming iron tablets (subgroups I and III) compared to subgroups without history of iron consumption (subgroups III and IV). There was no difference in the status of BMI and serum levels of albumin among the various subgroups of donors and community controls (Supplementary Table S1(a), Table S1(b)).

Oral iron tablet was the only form of regular non-dietary intake (other than alcohol) reported by HIV-1 positive as well as HIV negative donors. Repeated inspection of the iron tablets consumed by the donors revealed the preparations to be similar i.e. tablets of ferrous sulfate $(200 \mathrm{mg}$ strength with iron content of $30 \%$ in the form of elemental iron). These preparations were chosen by the donors due to easy availability in dispensaries and chemist shops as well as because of low cost. The quantity of intake of iron tablets in terms of range and average number of tablets consumed per day was comparable between the subgroups of HIV-1 positive and HIV negative donors with history of such intake. Serum levels of iron, ferritin and transferrin saturation (\%) as well as hemoglobin levels were higher in the subgroups consuming iron tablets regardless of HIV positivity compared to other subgroups without such history (Table 1).

\subsection{Immunological and Virological Characteristics of Donors at Enrolment}

There was no difference in viral load as well as CD4 + T Lymphocyte count at enrolment among the HIV-1 positive donors with or without history of oral iron intake ( $\log _{10}$ viral load $4.35 \pm 0.68$ vs $4.47 \pm 0.43$ and CD4 count $693 \pm 87$ vs 728 \pm 132 respectively; $\mathrm{p}=0.23$ and 0.08 respectively, data not shown in table).

Estimation of Th1 and Th2 types of cytokines in serum at enrolment indicated a relative dominance of Th2 type cytokines viz. IL- 4 and IL-10 over Th1 type cytokines viz. IL-2 and IFN- $\gamma$ in donors consuming iron compared to subgroups without such history regardless of HIV positivity (Table 2). In the iron consuming subgroup of HIV-1 positive donors, there was significant negative correlation between the serum ferritin levels and levels of Th1 type of cytokines i.e. IL-2 and IFN- $\gamma$ ( $\mathrm{r}$ value $-0.53 ; \mathrm{p}<0.001$ and $\mathrm{r}$ value $-0.29 ; \mathrm{p}<0.02$ respectively) and significant positive correlation with levels of one of the Th2 category of cytokines 
Table 1. Serum iron parameters in blood donors in relation to positivity for history of oral iron intake.

\begin{tabular}{|c|c|c|c|c|c|c|c|c|c|}
\hline \multicolumn{2}{|l|}{ Baseline variables } & \multicolumn{2}{|c|}{ HIV-1 positive } & \multicolumn{2}{|c|}{ HIV negative } & \multirow{2}{*}{$\begin{array}{l}\text { Community } \\
\text { control (Sgr V) }\end{array}$} & \multicolumn{3}{|c|}{$P$ value } \\
\hline \multicolumn{2}{|l|}{ (at enrolment) } & $\begin{array}{l}\text { Fe pos } \\
\text { (Sgr I) }\end{array}$ & $\begin{array}{l}\text { Fe neg } \\
\text { (SgrII) }\end{array}$ & $\begin{array}{l}\text { Fe pos } \\
\text { (SgrIII) }\end{array}$ & $\begin{array}{c}\text { Fe neg } \\
\text { (SgrIV) }\end{array}$ & & Overall & I vs II & III vs IV \\
\hline & & $\mathrm{n}=60$ & $\mathrm{n}=58$ & $\mathrm{n}=30$ & $\mathrm{n}=50$ & $\mathrm{n}=40$ & & & \\
\hline Consumption of iron & Range & $6-14$ & $\mathrm{NA}^{*}$ & $4-14$ & $\mathrm{NA}^{*}$ & $\mathrm{NA}^{*}$ & & & \\
\hline tablets/day & No & $9.97 \pm 1.8^{* *}$ & $\mathrm{NA}^{*}$ & $9.70 \pm 2.6$ & $\mathrm{NA}^{*}$ & $\mathrm{NA}^{*}$ & & & \\
\hline Hemoglobin $(\mathrm{gm} / \mathrm{dl})^{* * *}$ & & $12.9 \pm 0.39$ & $12.6 \pm 0.26$ & $12.7 \pm 0.32$ & $12.5 \pm 0.22$ & $12.8 \pm 0.21$ & $<0.001$ & $<0.001$ & 0.03 \\
\hline Serum iron $(\mu \mathrm{mol} / \mathrm{l})^{* * *}$ & & $40.1 \pm 5.49$ & $17 \pm 3.33$ & $41.2 \pm 4.6$ & $16.2 \pm 3.3$ & $16.6 \pm 3.21$ & $<0.001$ & $<0.001$ & $<0.001$ \\
\hline Serum Ferritin $(\mu \mathrm{g} / \mathrm{l})^{* * *}$ & & $349 \pm 106$ & $86 \pm 16$ & $371 \pm 80$ & $77 \pm 21$ & $90 \pm 24$ & $<0.001$ & $<0.001$ & $<0.001$ \\
\hline Transferrin saturation (\%) & & $65.3 \pm 9.5$ & $30.3 \pm 4.4$ & $70.1 \pm 5.7$ & $32.5 \pm 5.9$ & $31.4 \pm 4.6$ & $<0.001$ & $<0.001$ & $<0.001$ \\
\hline
\end{tabular}

Note: Sgr I to V indicate Subgroups I to V; Fe pos and Fe neg indicate positive and negative history of oral iron intake. ${ }^{\star} \mathrm{NA}=\mathrm{Not}$ applicable. ${ }^{\star *} \mathrm{p}=0.56$ between subgroups I and III regarding number of oral iron tablet consumption/day. ${ }^{\star *}$ Levels are expressed as mean + SD in various subgroups.

Table 2. Serum cytokine levels in donors at enrolment (baseline) in relation to history of oral iron intake.

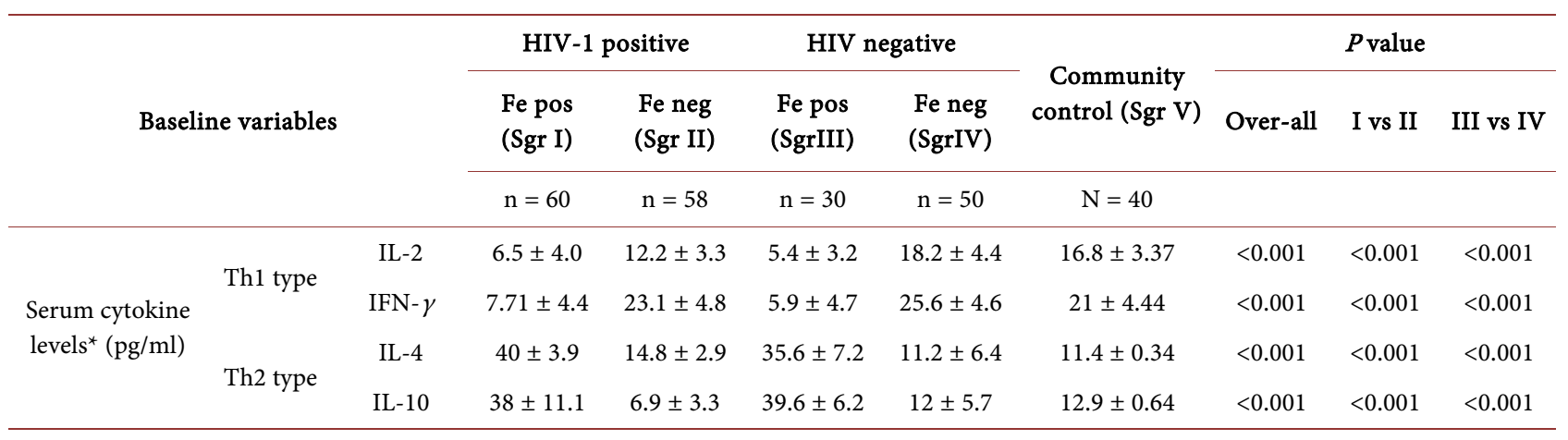

Note: i) Sgrs I to V indicate Subgroups I to V; Fe pos and Fe neg indicate positive and negative history of oral iron intake. ii) The levels of cytokines belonging to Th1 type (IL-2 and IFN- $\gamma$ ) and Th2 type (IL-4 and IL-10) were comparable among the two subgroups of donors with positive history of oral iron intake i.e. subgroup I and subgroup III. ${ }^{\star}$ All levels are expressed as mean \pm SD in various subgroups.

i.e. IL-4 ( $\mathrm{r}$ value $+0.41 ; \mathrm{p}<0.001$ ) while for the other Th2 category of cytokine i.e. IL-10, there was a trend for positive correlation although it failed to reach the level of statistical significance ( $r$ value $+0.22 ; p=0.09$ ). Similar trend of positive or negative associations were also evident in the iron consuming subgroup of HIV negative donors i.e. sub group III ( $\mathrm{r}$ value $-0.65,-0.51,+0.44$ and +0.57 for IL-2, IFN- $\gamma$, IL-4 and IL-10 respectively; $\mathrm{p}<0.001$ for all).

\subsection{Analysis of Symptom Free Duration}

Out of the $118 \mathrm{HIV}-1$ positive donors enrolled in the study comprising of 60 belonging to subgroup I and 58 belonging to subgroup II, a total of 10 donors comprising of 6 from subgroup I and 4 from subgroup II did not attend even the first follow up (at 6 months) and thus were excluded in analysis of symptom free duration. Pulmonary tuberculosis (PT) was the most common category of ARI encountered accounting for 38 out of $54(70.4 \%)$ of the HIV-1 positive donors revealing history of iron intake (i.e. subgroup I) while in subgroup of HIV-1 positive donors without history of iron intake (subgroup II) only 10 out of 54 i.e. 
18.5\% developed PT $\left(\chi^{2}=29.4 ; \mathrm{p}<0.001\right)$.

Median time for development of PT from enrolment was shorter compared to that for non-PT category of ARI in both subgroups I and II although the rapidity of development of PT category of ARI was much more marked among the former subgroup compared to similar cases in the later subgroup. The influence of iron intake on disease course was much less marked in non-PT category of cases (Figure 1, Table 3).

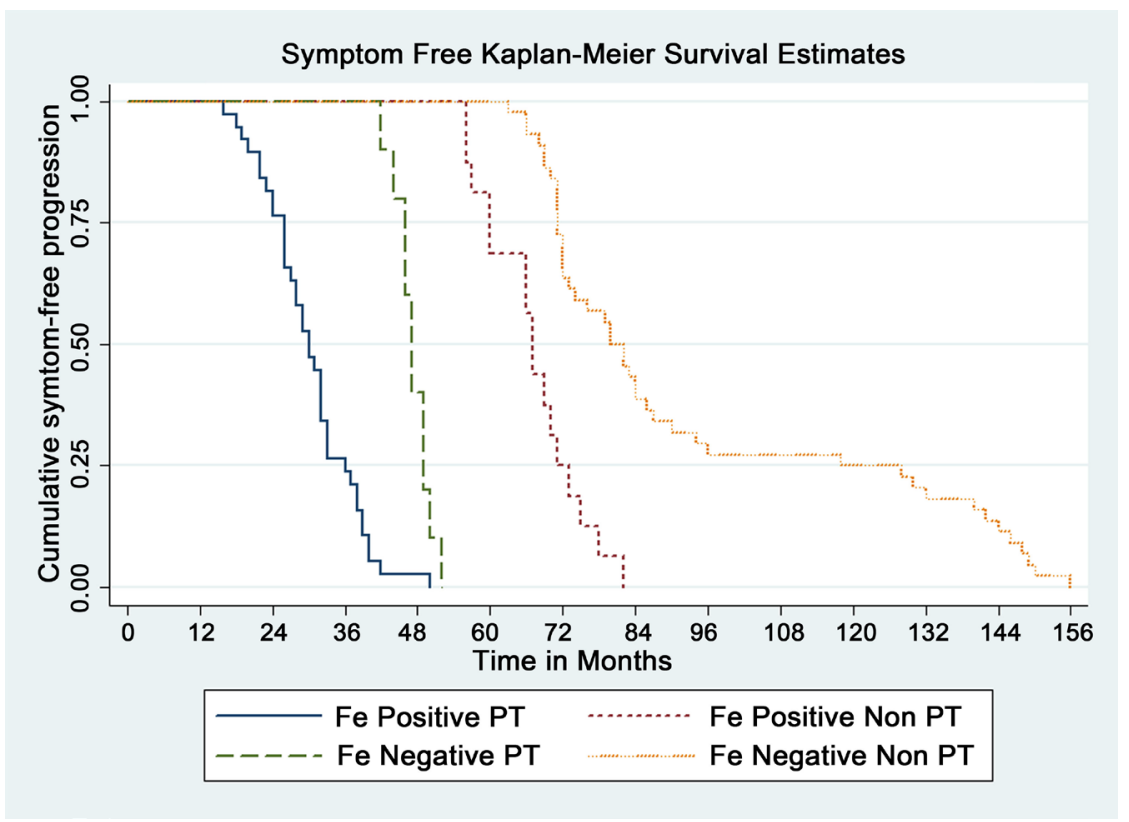

Figure 1. Symptom free duration among the ART naïve HIV-1 positive blood donors in relation to positive or negative history for oral iron intake (indicated as Fe pos or Fe neg respectively) and category of AIDS related illness (ARI) i.e. Pulmonary tuberculosis (PT) or other categories of ARI (non-PT).

Table 3. Comparison of symptom free and survival durations in HIV-1 positive blood donors among the two categories of AIDS Related Illness (ARI) developed i.e. pulmonary tuberculosis (PT) and illness other than PT (Non-PT) in relation to positive and negative history of iron intake (Fe pos and Fe neg respectively).

\begin{tabular}{|c|c|c|c|c|c|c|}
\hline \multirow{2}{*}{ Type of analysis } & \multirow{2}{*}{$\begin{array}{c}\text { Categories of HIV-1 positive } \\
\text { blood donors }\end{array}$} & \multirow{2}{*}{$\begin{array}{c}\text { Median duration } \\
\text { in months }(95 \% \mathrm{CI})\end{array}$} & \multicolumn{4}{|c|}{$P$ value } \\
\hline & & & Over all & i vs ii & iii vs iv & i vs iii \\
\hline \multirow{4}{*}{ Symptom free duration ${ }^{\star}(\mathrm{n}=108)$} & i. Fe pos PT (n - 38) & $30(26,32)$ & \multirow{4}{*}{$<0.001$} & \multirow{4}{*}{$<0.001$} & \multirow{4}{*}{$<0.001$} & \multirow{4}{*}{$<0.001$} \\
\hline & ii. Fe pos Non-PT $(\mathrm{n}=16)$ & $67(60,71)$ & & & & \\
\hline & iii. Fe neg PT $(n-10)$ & $47(42,49)$ & & & & \\
\hline & iv. Fe neg Non-PT $(\mathrm{n}=44)$ & $80(72,87)$ & & & & \\
\hline \multirow{4}{*}{ Survival duration $(\mathrm{n}=96)$} & i. Fe pos PT $(\mathrm{n}=38)$ & $47(42,48)$ & \multirow{4}{*}{$<0.001$} & \multirow{4}{*}{$<0.001$} & \multirow{4}{*}{$<0.001$} & \multirow{4}{*}{$<0.001$} \\
\hline & ii. Fe pos Non-PT $(\mathrm{n}=16)$ & $95(90,100)$ & & & & \\
\hline & iii. Fe neg PT $(n=10)$ & $71(65,76)$ & & & & \\
\hline & iv. Fe neg Non-PT $(\mathrm{n}=32)^{\star *}$ & $107(102,112)$ & & & & \\
\hline
\end{tabular}

${ }^{\star}$ Out of 118 donors enrolled in the study, a total of 10 donors who did not attend any follow up following initial enrolment (6 in Fe pos subgroup and 4 in Fe neg subgroup) were excluded from analysis of symptom free duration. ${ }^{* *}$ Out of the donors in the Fe neg subgroup with non-PT category of illness, those who survived beyond 2005 to be enrolled for ART $(n=12)$ were excluded for comparison of survival analysis in order to avoid confounding influence of ART on survival. 


\subsection{Analysis of Survival Duration}

Out of 108 HIV-1 positive donors that could be followed till development of ARI, 12 cases that survived till the point of introduction of ART in the country were excluded by right censoring in order to avoid confounding effect of ART on survival duration and only ART naïve HIV-1 infected donors (total 96) were included for survival analysis. Overall survival period was shorter in PT category of cases compared to those with non-PT category of cases regardless of history of oral iron intake. However, iron intake did not appear to influence the overall survival in non-PT category of cases (Figure 2, Table 3).

\subsection{Laboratory Parameters on Follow-Up}

\subsubsection{Laboratory Parameters at First Follow-Up (At Sixth Month)}

At sixth month of follow up, the iron consuming subgroup of HIV-1 positive blood donors showed significantly higher viral load and more rapid decline in CD4 + T Lymphocyte count during preceding 6 months compared to non-iron consuming subgroup ( $\log _{10}$ viral load $4.01 \pm 0.36$ vs. $3.86 \pm 0.39 ; \mathrm{p}<0.05$ and rate of fall in CD4 + T Lymphocyte count $16.2 \pm 4.92$ vs. $6.57 \pm 2.97$; $\mathrm{p}<0.001$, data not shown in table). There were significant positive correlations between iron load in terms of serum ferritin level and plasma viral load as well as rate of fall in CD4 $+\mathrm{T}$ Lymphocyte count at this point of time in the iron consuming subgroup (Figure 3). Correlation of serum levels of Th1 type and Th2 type of

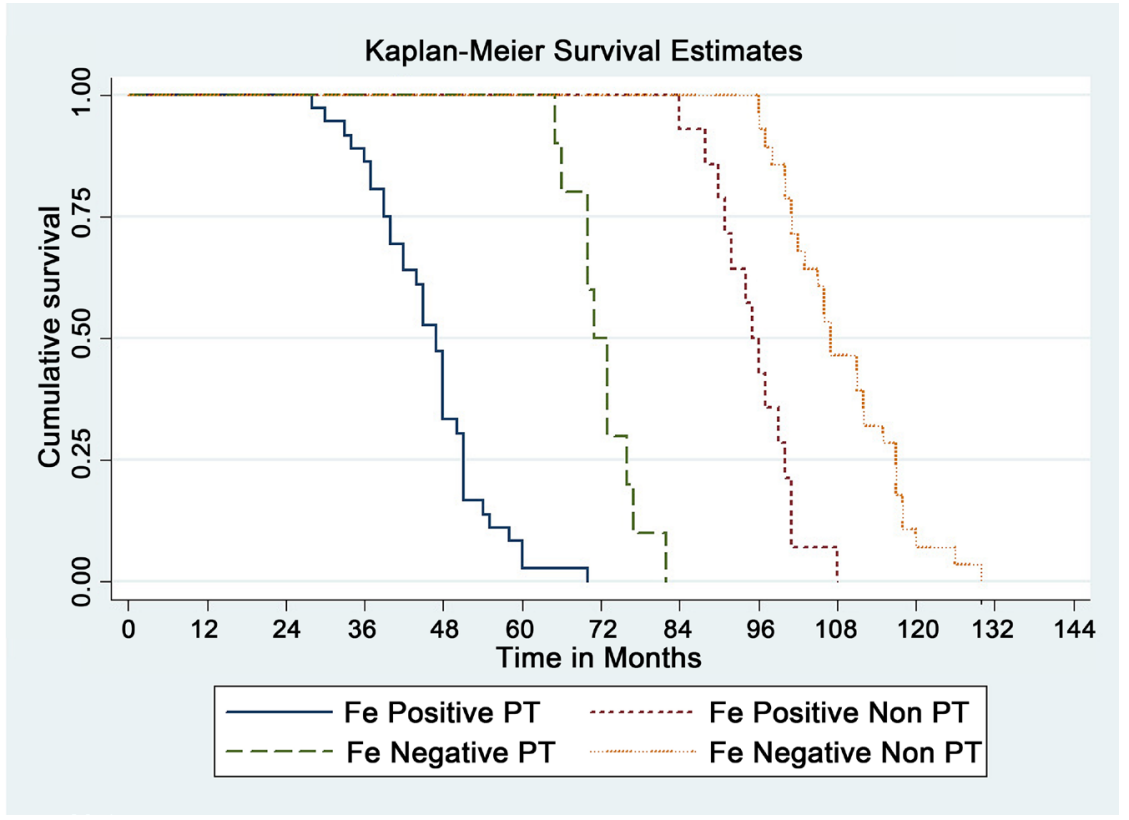

Figure 2. Survival duration among the ART naïve HIV-1 positive blood donors in relation to positive or negative history for oral iron intake (indicated as Fe pos or Fe neg respectively) and category of AIDS related illness (ARI) i.e. Pulmonary tuberculosis (PT) or other categories of ARI (non-PT). A total of $12 \mathrm{HIV}-1$ positive donors in the Fe neg subgroup, identified as long term non-progressors (LTNPs), survived beyond the point of introduction of ART in the country (in 2005) and thus were enrolled for ART. These donors have been excluded from survival analysis to avoid confounding effect of ART. 

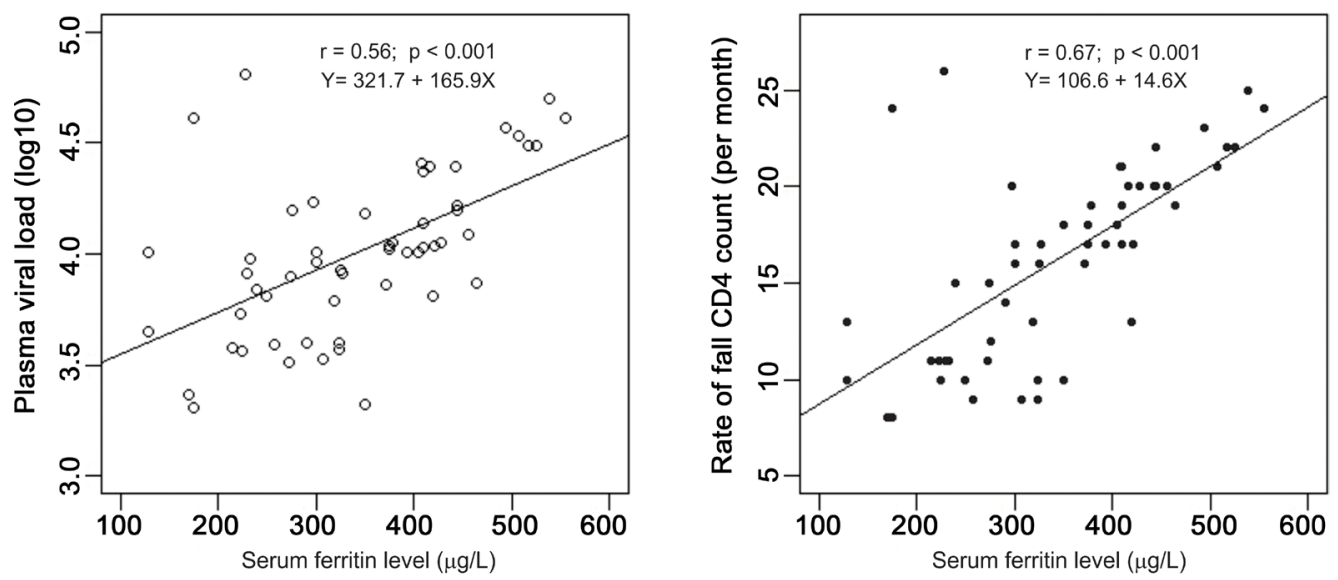

Figure 3. Correlation between serum ferritin level and viral load as well as rate of fall in CD4+ T lymphocyte count among the iron consuming subgroup of HIV-1 positive blood donors.

cytokines with rate of fall of CD4 count at 6 months of follow-up in the iron consuming subgroup of HIV-1 positive blood donors showed levels of IL-2 and IFN- $\gamma$ to bear a negative correlation ( $\mathrm{r}$ value $-0.68 ; \mathrm{p}<0.001$ and $-0.44 ; \mathrm{p}<$ 0.001 respectively) while that of IL- 4 and IL-10 to bear a positive correlation ( $\mathrm{r}$ value $+0.45 ; \mathrm{p}<0.001$ and $+0.47 ; \mathrm{p}<0.001$ respectively). On the other hand, in the non-iron consuming subgroup of HIV-1 positive blood donors no such correlation could be observed ( $\mathrm{r}$ values as $-0.17,-0.19,+0.18$ and +0.19 for IL-2, IFN- $\gamma$, IL-4 and IL-10 respectively; P value not significant in all comparisons).The HIV negative donors and community controls did not show any alteration in CD4 count or in serum cytokine levels at $6^{\text {th }}$ month of follow up compared to their enrolment values.

\subsubsection{Laboratory Parameters in Relation to the Category of ARI Developed on Follow-Up}

Among the HIV-1 positive donors, rate of decline in CD4 $+\mathrm{T}$ lymphocyte count, mean CD $4+\mathrm{T}$ lymphocyte count at the time of development of ARI, viral load at $6^{\text {th }}$ month except at the time of development of ARI were all recorded to be higher among cases developing PT category of ARI compared to cases with non-PT category in both subgroups I and II (Table 4).

Retrospective analysis of laboratory parameters at enrolment in relation to category of ARI developed on follow up revealed that among subgroup I donors, those developing PT on follow up had significantly higher serum iron load at enrolment compared to those who developed non-PT category of ARI, mean \pm SD of serum ferritin level $(\mu \mathrm{g} / \mathrm{L})$ as $382 \pm 93.1$ in the former category compared to $250 \pm 78.3$ in the later $(\mathrm{p}<0.001$, data not shown in table). Moreover, in the same subgroup, both symptom free duration as well as post-symptom survival duration in PT cases had negative correlations with the serum iron load at enrolment (Figure 4(a), Figure 4(b)).

Study of levels of three immune activation markers in serum i.e. $\operatorname{TNF} \alpha$, TNF-R p55 and TNF-R p75 revealed that regardless of HIV positivity the subgroups 
Table 4. Immunological and virological characteristics of the HIV-1 positive blood donors $\left(n=108^{\star}\right)$ in relation to category of AIDS Related Illness (ARI) i.e. PT versus non-PT.

\begin{tabular}{|c|c|c|c|c|c|c|c|}
\hline \multirow{3}{*}{ Parameters } & & \multicolumn{6}{|c|}{ History of oral iron intake } \\
\hline & & \multicolumn{3}{|c|}{ Positive (Sgr I; $\mathrm{n}=54$ ) } & \multicolumn{3}{|c|}{ Negative (Sgr II; $\mathrm{n}=54$ ) } \\
\hline & & $\mathrm{PT}$ & Non-PT & $P$ value & $\mathrm{PT}$ & Non-PT & $P$ value \\
\hline \multirow[t]{2}{*}{ Peripheral CD4+ T lymphocyte count } & Rate of fall/month ${ }^{* *}$ & $18.7 \pm 3.5$ & $10.25 \pm 1.4$ & $<0.001$ & $11 \pm 2.49$ & $5.6 \pm 2$ & $<0.001$ \\
\hline & At onset of ARI & $389 \pm 14$ & $222 \pm 40$ & $<0.001$ & $340 \pm 42$ & $165 \pm 35$ & $<0.001$ \\
\hline \multirow[t]{2}{*}{ Plasma viral load $\left(\log _{10}\right)$} & At $6^{\text {th }}$ month of follow up & $4.16 \pm 0.3$ & $3.64 \pm 0.21$ & $<0.001$ & $4.12 \pm 0.15$ & $3.81 \pm 0.41$ & $<0.001$ \\
\hline & At onset of ARI & $4.72 \pm 0.11$ & $5 \pm 0.06$ & $<0.001$ & $4.72 \pm 0.19$ & $5.14 \pm 0.09$ & $<0.001$ \\
\hline
\end{tabular}

Note: Sgr I and II indicate Subgroups I and II. *A total of 10 donors comprising of 6 in Subgroup I and 4 in Subgroup II did not attend any follow up following enrolment and thus have not been included in the above table. ${ }^{*}$ Calculated for first 6 month of post-enrolment period.
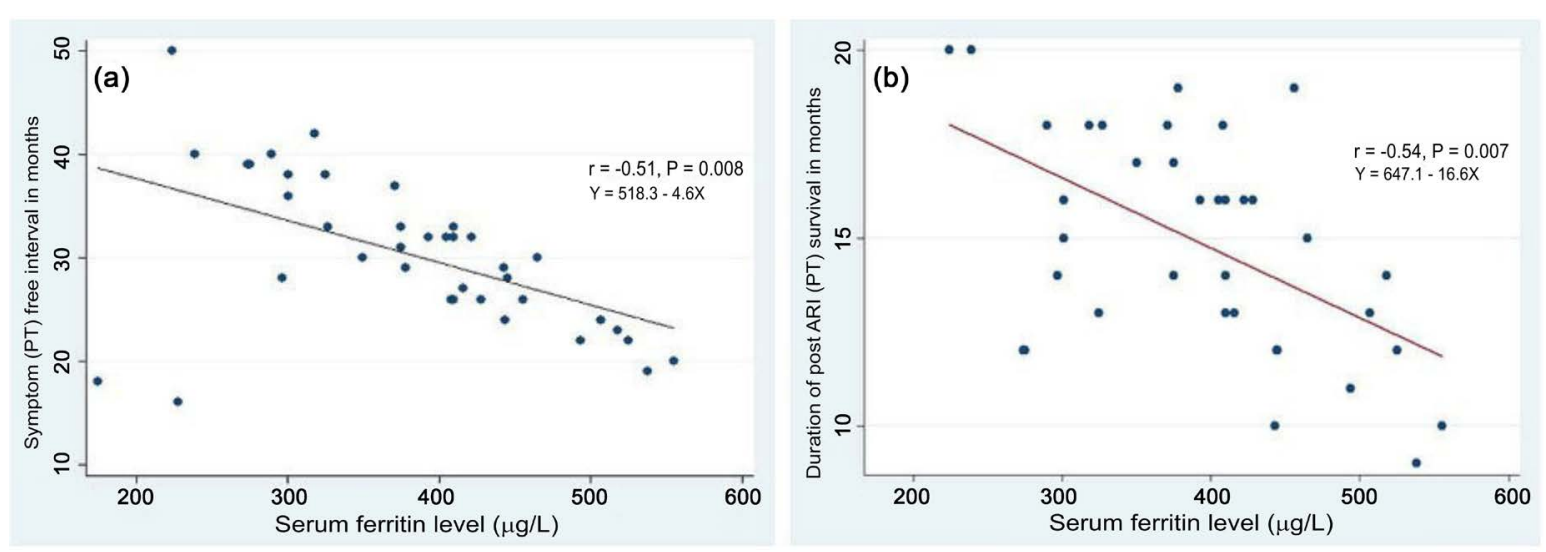

Figure 4. Correlation between serum ferritin level and (a) symptom free duration as well as (b) post-ARI (PT) survival duration in the PT cases among iron consuming subgroup of HIV-1 positive blood donors.

of donors consuming iron (subgroups I and III) showed higher levels of activation at baseline compared to subgroups without any such history (subgroups II and IV). The median levels (pg/ml) of TNF $\alpha$, TNFR p55 and TNFR p75 was recorded as 26, 3.18 and 10 in subgroup I versus 1.0, 1.11 and 2.65 in subgroup II and 26, 2.7 and 6 in subgroup III versus 1.3, 1.4 and 1.3 in subgroup IV (overall $\mathrm{p}<0.001$ on multiple comparisons as well as on individual comparisons between subgroups I and II and between subgroups III and IV for all three immune activation markers). Such higher level of activation in subgroups I and III compared to subgroups II and IV continued being reflected at subsequent follow up as well for all the three markers except at the point of ARI where the subgroup II showed level higher than subgroup I in only one out of three markers studied i.e. TNF- $\alpha$ (Figure 5).

\section{Discussion}

In the present study, the professional blood donors were all males with narrow range of age distribution in accordance with the reported age and sex profile of the professional blood donors in this country [1] [2]. Majority of the donors with positive history of iron intake, regardless of HIV positivity revealed the 

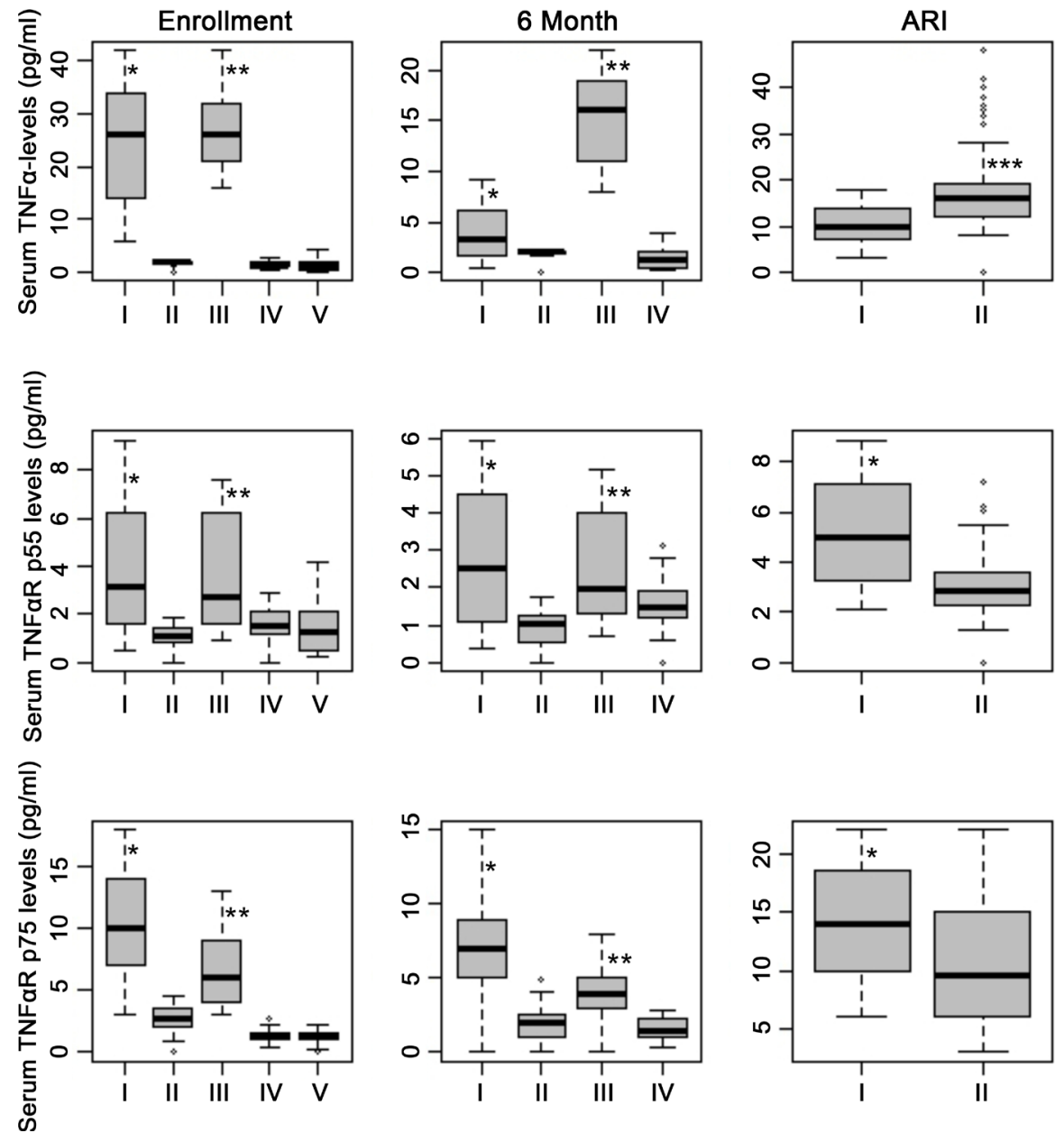

${ }^{\star}$ Indicates significantly higher level in Subgroup I vs II $(\mathrm{p}<0.01) ;{ }^{* *}$ Indicates significantly higher level in Subgroup III vs IV $(\mathrm{p}<0.01)$; ${ }^{* *}$ Indicates significantly higher level in Subgroup II vs I $(\mathrm{p}<$ $0.01)$.

Figure 5. Box plot showing serum levels of TNF- $\alpha$, TNFR p55 and TNFR p75 at enrolment i.e. zero month $(0 \mathrm{~m})$ and at various points of follow up i.e. 6 months $(6 \mathrm{~m})$, and at the point of development of ARI. The III and IV subgroups of donors i.e. the HIV negative donors did not develop ARI and thus do not feature in column of ARI. The non-donor control group, denoted as subgroup V, was assessed at enrolment $(0 \mathrm{~m})$ only.

practice of donating at frequencies higher than the recommended national and international guideline [23] [24].

Despite high frequency of donation, the donors had unimpaired hemoglobin level that could be due to the prevalent practice of taking oral iron tablets liberally enough to compensate the deficiency resulting from high frequency of donation. On the contrary rather, the donors with history of iron intake had indications of iron over load as reflected by serum levels of iron, ferritin and transferrin saturation (\%), an observation that deserves attention. In India, one unit of donated blood amounts to a maximum of approximately $350 \mathrm{ml}$ [24]. Thus, a donor donating once in 4 weeks or 28 days (maximum frequency reported in the present study) is likely to suffer blood loss equivalent to approximately $12.5 \mathrm{ml}$ per day amounting to an iron loss of about $6.25 \mathrm{mg}$ ( $1 \mathrm{ml}$ of blood contains $\sim 0.5$ 
$\mathrm{mg}$ of iron) [25]. Assuming, an average of $10 \%$ of absorption of elemental iron from oral iron preparations under physiological condition [26], oral intake of two to three tablets of ferrous sulphate of $200 \mathrm{mg}$ strength containing $30 \%$ or 60 mg of elemental iron should be more than adequate to compensate the average iron loss per day for a donor donating $350 \mathrm{ml}$ of blood every 4 weeks. Thus it was evident in the present study that the range of consumption of iron reported by donors in both HIV-1 positive and HIV negative subgroups were clearly much higher than the requirement. The biochemical parameters in serum among the donors with history of oral iron consumption provides a definite evidence of iron overload regardless of any possible inaccuracy in the reporting by the donors regarding the brand or quantity of iron tablet consumed by the donors. Body iron status is normally maintained through a physiological regulatory mechanism in which its absorption is balanced against the body requirement increasing only in deficient state and in the event of ingestion of amount more than requirement, the excess amount is lost through exfoliation of intestinal epithelial cells containing absorbed iron [27]. However, iron absorption is reported to increase beyond requirement in the event of concomitant intake of alcohol intake [28] [29] [30]. This could be considered an important mechanism for iron over load in subjects of our study since there was concomitant increase in the magnitude of consumption of alcoholic drinks in the subgroups with history of iron intake. This possibility is supported by the reports of iron overload in the population of Zimbabweans and Southern African rural blacks having prolonged history of consumption of traditional beer in iron containers [31] [32].

Many studies have pointed out that single point estimation of CD4 + T lymphocyte counts cannot always be accepted alone as a reliable predictor for disease progression in HIV-1 infection [33] [34]. In our previous study on HIV-1 positive children, baseline CD4 + T lymphocyte count could not be correlated with disease progression and rate of decline of CD4+ T lymphocyte counts was found to be more reliable predictor of future course of illness which is in agreement with the findings of negative correlation between the rate of fall in CD4 + $\mathrm{T}$ lymphocyte count with the disease progression in the subgroup of HIV-1 positive donors with history of oral iron intake [17]. Plasma viral load at base line was not helpful either in predicting course of disease in the present study. However viral load assessed at 6 months predicted well negatively with symptoms free duration, which is in agreement with the generally accepted view that the viral set point i.e. the stable viral load attained between 6 months to 1 year, is a more reliable predictor of disease progression than initial viral load [35] [36].

It is accepted that qualitative defect in $\mathrm{T}$ cell function reflected by change in serum cytokine profile from Th1 dominant Th2 dominant one precede quantitative decline in CD4 count in the early asymptomatic stage of HIV-1 infection [37] which corroborates with the positive and negative correlations observed for Th2 (IL-4, IL-10) and Th1 (IL-2, IFN- $\gamma$ ) type of cytokines respectively with subsequent decline in $\mathrm{CD} 4+\mathrm{T}$ lymphocyte count in the present study. 
PT was the most common ARI encountered in the HIV-1 infected blood donors in the present study, accounting for $44.8 \%$ of cases in accordance with reports from developing countries including India where PT has been reported to be the common illness in HIV-1 infected individuals with incidence ranging from $42 \%$ to $80 \%$ due to high prevalence of tuberculosis [38] [39] [40]. PT was also the first presentation of HIV-1 infection at an early stage after seroconversion compared to various non-PT ARI. PT has been reported at relatively early stage of illness in HIV-1 infected individuals even in the face of normal or minimally depressed CD4 $+\mathrm{T}$ lymphocyte count due to subtle defects in CD4 $+\mathrm{T}$ lymphocyte function induced by HIV contributing to greater susceptibility to $M$. tuberculosis [41] which is substantiated in our study where the mean CD4 + T lymphocyte count in the cases diagnosed with PT was significantly higher compared to other ARI. HIV-1 infection co-infected with $M$. tuberculosis bas been reported to be characterized by higher activation marker like TNF- $\alpha$ compared to those without such co-infection suggesting tuberculosis to be an important underlying cause of rapid progression of HIV-1 disease explaining significantly shorter post PT survival period in the HIV-1 positive donors compared to other varieties of ARI in the present study [42]. Median time to death in the cohort of present study ( 80 months) is consistent with the reports from developing countries like Uganda [38], Cote d'Ivoire [43] and Kenya [44] and Haiti [45].

In the present study the subgroup of HIV-1 positive donors with history of oral iron intake, developed high incidence of pulmonary tuberculosis (more than $70 \%$ ) on follow up. Role of iron overload in predisposing infection due to $M$. tuberculosis is well recognized [46]. Thus it would be worth considering in the present study if high incidence of PT in subgroup of HIV-1 positive donors with history of iron intake could be due to onset of immunological deterioration induced by HIV-1 or iron overload could as well be an independent consideration. The later possibility is strengthened by the finding of $4(13.3 \%)$ cases of PT encountered among the group of $30 \mathrm{HIV}$ negative donors with the history of oral iron intake compared to none in the HIV negative donors without such history. Moreover, such consideration derives further support from the significant negative correlation observed between the serum ferritin level and duration of symptom free interval as well as survival duration in the subgroup of HIV-1 positive donor consuming oral iron in the present study. Several studies have indeed pointed out the role of excess iron accelerating in the pathogenesis of HIV-1 infection possibly due to increased replication of HIV-1 resulting from elevation of nuclear transcription factor kappa $\beta$ [47], facilitation of growth of $M$. tuberculosis [48] and impaired cell mediated immune mechanism [49]. It has also been suggested that ingestion of oral iron may result in subclinical damage to intestinal mucosa resulting in invasion of microbes leading to immune activation [49]. Expression of several immune activation markers are known to correlate with clinical disease progression in HIV infection with demonstrable predictive value on HIV disease course, independent of plasma HIV RNA, when measured during early infection, or even before actual seroconversion [10] [11] [12]. The 
present study indicated that at very early stage of HIV-1 infection even before impairment of CD4 + T lymphocyte count, the disease course can be predicted by the level of immune activation. Admittedly however, the relationship between prior history of iron intake and immune activation failed to be evident for a single activation marker i.e. TNF- $\alpha$ out of the three studied only at the ARI stage that could be due to many complex factors at ARI stage influencing its level as evident from the large number of samples showing values identified as outliers (Figure 5). Thus it may be conceivable that excessive ingestion of iron by the subgroups of donors may have been responsible for inducing a state of immune activation coupled with an altered cellular immune status characterized by alteration in the Th1/Th2 cytokine profile. Further, it is more likely that such immunological imbalance was independent of HIV-1 virus since matched HIV negative blood donors with the practice of iron intake demonstrated similar type of imbalance.

Overall the present study indicates a strong possibility of iron load to be responsible for immune deregulation in HIV-1 infection facilitating a scenario for acquisition of tuberculosis and rapid disease progression in HIV-1 infected individuals thereby raising concern about the need for proper monitoring of iron status before recommending oral iron in HIV-1 infection e.g.in case of pregnancy.

\section{Acknowledgements}

The authors are grateful to Mrs. M. Kalaivani and Mr. Ashish Datt Upadhyay, both Scientists, Department of Biostatistics, All India Institute of Medical Sciences, New Delhi and Dr Onkar Swami, Ph.D scholar, University of Delhi for help in the statistical analysis of some data and to Dr. Boney Devi, an MPH Scholar, for some constructive suggestions in the analysis of data. The authors are also grateful to the blood banks in the city of Delhi and other cities of North India for referring the donors screened to be positive for HIV-1 infection.

\section{References}

[1] Chattopadhya, D., Riley, L.W. and Kumari, S. (1991) Behavioral Risk Factors for Acquisition of HIV Infection and Knowledge about AIDS among Male Professional Donors in Delhi. Bulletin of the World Health Organization, 69, 319-323.

[2] Singh, R., Kapur, S. and Mittal, A. (1995) Rising Trend of HIV Positive Individuals among Blood Donors in Delhi. Indian Journal of Sexually Transmitted Diseases, 16, $15-17$.

[3] Wadia, M.R. and Karve, S.R. (1992) Rising Trend of HIV Infection with Special Reference to Blood Donors. The Journal of the Association of Physicians of India, 40, 513-515.

[4] Kumarswamy, N., Solomon, S., Flanigan, T.P., Hemlatha, R., Thyagarajan, S.P. and Mayer, K.H. (2003) Natural History of Human Immunodeficiency Virus Disease in Southern India. CID, 36, 79-85. https://doi.org/10.1086/344756

[5] Swami, O.S., Chattopadhya, D., Grover, G., Kumar and Baveja, U.K. (2006) Role of HCV Co-Infection towards Disease Progression and Survival in HIV-I Infected 
Children: A Follow up Study of 10 Years. Journal of Tropical Pediatrics, 52, 206-211. https://doi.org/10.1093/tropej/fmi103

[6] Swami, O.S., Chattopadhya, D. and Grover, G. (2007) Nonparametric Estimation of the Incubation Period of AIDS with Left Truncation and Right Censoring. Journal of Data Science, 5, 289-296.

[7] Amo, J.D., Petruckevitch, A., Phillips, A., Johnson, A.M., Stephenson, J., Desmond, M., Hanscheid, T., et al. (1998) Disease Progression and Survival in HIV-1 Infected Africans in London. AIDS, 12, 1203-1209. https://doi.org/10.1097/00002030-199810000-00013

[8] Enger, C., Graham, N., Peng, Y., Chmiel, J.S., Kingsley, L.A., Detels, R., et al. (1996) Survival from Early, Intermediate, and Late Stage of HIV Infection. JAMA, 275, 1329-1334. https://doi.org/10.1001/jama.1996.03530410043031

[9] Guenter, P., Muurahainen, N., Simons, G., Kosok, A., Cohan, G.R., Rudenstein, R., et al. (1993) Relationship among Nutritional Status, Disease Progression and Survival in HIV Infection. Journal of Acquired Immune Deficiency Syndromes, 6, 1130-1138.

[10] Leng, Q., Borkow, G., Weisman, Z., Stein, M., Kalinkovich, A. and Bentwich, Z. (2001) Immune Activation Correlates Better than HIV Plasma Viral Load with CD4 T Cell Decline during HIV Infection. Journal of Acquired Immune Deficiency Syndromes, 27, 389-397. https://doi.org/10.1097/00126334-200108010-00010

[11] Deeks, S.G., Kitchen, C.M., Liu, L., Guo, H., Gascon, R., Narvaez, A.B., et al. (2004) Immune Activation Set Point during Early HIV Infection Predicts Subsequent CD4+ T Lymphocyte Changes Independent of Viral Load. Blood, 104, 942-947. https://doi.org/10.1182/blood-2003-09-3333

[12] Hazerberg, M.D., Otto, S.A., van Benthem, B.H., Ross, M.T., Coutinho, R.A., Langer, J.M., et al. (2003) Persistent Immune Activation in HIV-1 Infection Is Associated with Progression to AIDS. AIDS, 17, 1881-1888. https://doi.org/10.1097/00002030-200309050-00006

[13] Chattopadhya, D., Aggarwal, R., Sen, S., Kumari, S. and Verghese, T. (1996) Lack of Evidence of HIV-2 Infection among Multi-Transfused Thalassemic Children in the City of Delhi. Journal of Tropical Pediatrics, 42, 116-117. https://doi.org/10.1093/tropej/42.2.116-a

[14] Indian Council of Medical Research (1999) Nutritional Requirements and Recommended Dietary Allowances for Indians. National Institute of Nutrition, Hyderabad.

[15] Chattopadhya, D., Saha, K., Chakrabarty, A.K., Rao, K.N., Patil, S.K. and Dusaj, I.S. (1992) Nutritional Status of Children of Urban Leprosy Patients Staying at Preventoria Based on Biochemical Parameters. European Journal of Clinical Nutrition, 46, 885-895.

[16] Aggarwal, V., Prakash, C., Yadav, S. and Chattopadhya, D. (1997) Prevalence of Transfusion Associated Infection in Multi-Transfused Children in Relation to Mandatory Screening of Human Immunodeficiency Virus (HIV) Infection in Donated Blood. The Southeast Asian Journal of Tropical Medicine and Public Health, 28, 699-706.

[17] Chattopadhya, D., Baveja, U.K., Bose, M. and Kumar, A. (2002) Disease Progression Marker during Asymptomatic Phase of HIV-1 Infected Children with CD4+ Lymphocyte Values: Evaluation of Repeat CD4+ Lymphocyte vs. Other Immunological Parameters. Journal of Tropical Pediatrics, 48, 340-347.

https://doi.org/10.1093/tropej/48.6.340 
[18] World Health Organization (1994) Expanded WHO Case Definition for AIDS Surveillance in Adults and Adolescents. The Weekly Epidemiological Record, 69, 273-275.

[19] Fischbach, F.T. and Dunning, M.B. (2009) A Manual of Laboratory and Diagnostic Tests. Lippincott Williams \& Wilkins, Philadelphia.

[20] Morgan, D., Maude, G.H., Malamba, S., Okongo, M.J., Wagner, H.U., Mulder, D.W., et al. (1997) HIV-1 Disease Progression and AIDS Defining Disorder in Rural Uganda. The Lancet, 350, 245-250. https://doi.org/10.1016/S0140-6736(97)01474-8

[21] Whalen, C.C., Nsubuga, P., Okwera, A., Johnson, J.L., Hom, D.L., Michael, N.L., et al. (2000) Impact of Pulmonary Tuberculosis on Survival of HIV-Infected Adults: A Prospective Epidemiologic Study in Uganda. AIDS, 14, 1219-1228. https://doi.org/10.1097/00002030-200006160-00020

[22] Rosner, B. (2000) Fundamentals of Biostatistics. 5th Edition, Duxbury Press, Belmont.

[23] World Health Organization (2002) Safe Blood and Blood Products, Module 1. WHO, Geneva.

[24] Director General of Health Services (1988) Development Strategies on Blood Transfusion Service in India. DGHS, New Delhi.

[25] Powell, L.W. (2005) Hemochromatosis. In: Kasper, D.L., Braunwald, E. and Fauci, A.S., Eds., Harrison's Principle of Internal Medicine, 16th Edition, Vol. 2, Chapter 342, McGraw-Hill, New York.

[26] Alleyne, M., Horne, M.K. and Miller, J.L. (2008) Individualized Treatment for Iron Deficiency Anemia in Adults. American Journal of Medicine, 121, 943-948. https://doi.org/10.1016/j.amjmed.2008.07.012

[27] Guyton, A.C. and Hall, J.E. (2006) Textbook of Medical Physiology. 11th Edition, W.B. Saunders Company, Harcourt Asia Pvt Ltd., Singapore.

[28] Duane, P., Raja, K.B., Simpson, R.J. and Peters, T.J. (1992) Intestinal Iron Absorption in Chronic Alcoholics. Alcohol and Alcoholism, 27, 539-544.

[29] Gordeuk, V.R. (1992) Hereditary and Nutritional Overload. Baillière's Clinical Haematology, 5, 169-176. https://doi.org/10.1016/S0950-3536(11)80040-5

[30] Moyo, V.M., Mandishona, E., Hasstedt, S.J., Gangaidzo, I.T., Gomo, Z.A., Khumalo H., et al. (1998) Evidence of Genetic Transmission in African Iron over Load. Blood, 91, 1076-1082.

[31] Gordeuk, V.R., Boyd, R.D. and Brittenham, G.M. (1986) Dietary Iron Overload Persists in Rural Sub-Saharan Africa. The Lancet, 1, 1310-1313. https://doi.org/10.1016/S0140-6736(86)91230-4

[32] Friedman, B.M., Baynes, R.D., Bothwell, T.H., Gordeuk, V.R., Macfarlane, B.J., Lamparelli, R.D., et al. (1990) Dietary Iron Overload in South African Rural Blacks. South African Medical Journal, 78, 301-305.

[33] Langford, S.E., Ananworanich, J. and Cooper, D.A. (2007) Predictors of Disease Progression in HIV Infection: A Review. AIDS Research and Therapy, 4, 11. https://doi.org/10.1186/1742-6405-4-11

[34] Lepri, A.C., Sabin, C.A., Pizzotti, P., England, P.D., Phillips, A.N. and Razza, G. (1997) Is There a General Tendency for CD4 Lymphocyte Decline to Speed up during Human Immunodeficiency Virus Infection? Evidence from Italian Seroconversion Study. The Journal of Infectious Diseases, 175, 775-780. https://doi.org/10.1086/513970

[35] CASCADE Collaboration (2000) Time from HIV-1 Sero-Conversion to AIDS and 
Death before Widespread Use of Highly Active Antiretroviral Therapy: A Collaborative Reanalysis. The Lancet, 355, 1131-1137. https://doi.org/10.1016/S0140-6736(00)02061-4

[36] Lavreys, L., Baeten, J.M., Chohan, V., McClelland, R.S., Hassen, W.M., Richardson, B.A., et al. (2006) Higher Set Point Plasma Viral Load and More Severe Acute HIV Type1 (HIV-1) Illness Predict Mortality among High Risk HIV-1 Infected African Woman. Clinical Infectious Diseases, 42, 1333-1339. https://doi.org/10.1086/503258

[37] Miedema, F., Petit, A.J., Terpstra, F.G., Schattenkerk, J.K., de Wolf, F., Al, B.J., et al. (1988) Immunological Abnormalities in Human Immunodeficiency Virus (HIV)-Infected Asymptomatic Homosexual Men. The Journal of Clinical Investigation, 82, 1908-1914. https://doi.org/10.1172/JCI113809

[38] Morgan, D., Mahe, C., Mayanja, B. and Whitworth, J.A.G. (2002) Progression to Symptomatic Disease in People Infected in HIV-1 Infection in Rural Uganda: Prospective Cohort Study. BMJ, 324, 193-196. https://doi.org/10.1136/bmj.324.7331.193

[39] Raviglione, M.C., Narain, J.P. and Kochi, A. (1992) HIV-Associated Tuberculosis in Developing Countries: Clinical Features, Diagnosis and Treatment. Bulletin of the World Health Organization, 70, 515-526.

[40] Barnes, P.F., Bloch, A.B., Davidson, P.T. and Snider, D.E. (1991) Tuberculosis in Patients with Human Immunodeficiency Virus Infection. The New England Journal of Medicine, 324, 1644-1650. https://doi.org/10.1056/NEJM199106063242307

[41] Orme, I.M., Anderson, P. and Boom, W.H. (1993) Lymphocyte Response to Mycobacterium tuberculosis. The Journal of Infectious Diseases, 167, 1481-1487. https://doi.org/10.1093/infdis/167.6.1481

[42] Leroy, V., Salmi, L.R., Dupon, M., Sentilhes, A., Texier-Maugien, J., Dequae, L., et al. (1997) Progression of Human Immunodeficiency Virus in Patients with Tuberculosis Disease. American Journal of Epidemiology, 145, 293-300. https://doi.org/10.1093/oxfordjournals.aje.a009105

[43] Ackah, A.N., Coubibaly, D., Digbeu, H., Diallo, K., Vetter, K.M., Coulibaly, I.M., et al. (1995) Response to Treatment, Mortality and CD4 Lymphocyte Counts in HIV-Infected Patients with Pulmonary Tuberculosis in Abidjan, Cote d'lvoire. The Lancet, 345, 607-610. https://doi.org/10.1016/S0140-6736(95)90519-7

[44] Anzala, O.A., Nagelkerke, N.J., Bwayo, J.J., Holton, D., Moses, S., Ngugi, E.N., et al. (1995) Rapid Progression to Disease in African Sex Workers with Human Immunodeficiency Virus Type 1 Infection. The Journal of Infectious Diseases, 171, 686-689. https://doi.org/10.1093/infdis/171.3.686

[45] Deschamps, M.M., Fitzgerald, D.W., Pape, J.W. and Johnson, W.D. (2000) HIV Infection in Haiti: Natural History and Disease Progression. AIDS, 14, 2515-2521. https://doi.org/10.1097/00002030-200011100-00014

[46] Cronje, L., Edmondson, N., Eisenach, K.D. and Bornman, L. (2005) Iron and Iron Chelating Agents Modulate Mycobacterium tuberculosis Growth and Monocyte-Macrophage Viability and Effector Functions. FEMS Immunology \& Medical Microbiology, 45, 103-112. https://doi.org/10.1016/j.femsim.2005.02.007

[47] Sappey, C., Boelaert, J.R., Legrand-Poels, S., Forceille, C., Favier, A. and Piette, J. (1995) Iron Chelation Decreases NF-kB and HIV Type-1 Activation Due to Oxidative Stress. AIDS Research and Human Retroviruses, 11, 1049-1061. https://doi.org/10.1089/aid.1995.11.1049

[48] Gangaidzo, I.T., Moyo, V.M., Mvundura, E., Aggrey, G., Murphree, N.L., Khumalo, H., et al. (2001) Association of Pulmonary Tuberculosis with Increased Dietary Iron. The Journal of Infectious Diseases, 184, 936-939. 
https://doi.org/10.1086/323203

[49] De Sousa, M. (1989) Immune Lymphocyte Function in Iron Overload. Clinical \& Experimental Immunology, 75, 1-6. 


\section{Supplementary Tables}

Table S1. (a) HIV related risk behavior, nutritional and anthropometric parameters among various subgroups of blood donors in relation to history of oral iron intake; (b) Statistical analysis for HIV related risk behavior, nutritional and anthropometric parameters among various subgroups of blood donors in relation to history of oral iron intake.

(a)

\begin{tabular}{|c|c|c|c|c|c|c|c|}
\hline & \multirow{3}{*}{ Baseline variables } & & \multicolumn{2}{|c|}{ HIV-1 positive } & \multicolumn{2}{|c|}{ HIV negative } & \multirow{2}{*}{$\begin{array}{c}\text { Community } \\
\text { control } \\
\text { (Sgr V) }\end{array}$} \\
\hline & & & $\begin{array}{l}\text { Fe pos } \\
\text { (Sgr I) }\end{array}$ & $\begin{array}{l}\text { Fe neg } \\
\text { (Sgr II) }\end{array}$ & $\begin{array}{c}\text { Fe pos } \\
\text { (Sgr III) }\end{array}$ & $\begin{array}{c}\text { Fe neg } \\
\text { (Sgr IV) }\end{array}$ & \\
\hline & & & $\mathrm{n}=60$ & $\mathrm{n}=58$ & $\mathrm{n}=30$ & $\mathrm{n}=50$ & $\mathrm{n}=40$ \\
\hline \multirow{3}{*}{ Blood donation frequency } & $\leq 6$ weeks & No (\%) & $51(85)$ & $0(0)$ & $24(80)$ & $0(0)$ & \multirow{3}{*}{$\mathrm{NA}^{* *}$} \\
\hline & $>6$ weeks $-<3$ months & No (\%) & $9(15)$ & $3(5.2)$ & $6(20)$ & $0(0)$ & \\
\hline & $\geq 3$ months & No (\%) & $0(0)$ & $55(94.8)$ & $0(0)$ & $50(100)$ & \\
\hline \multirow{5}{*}{$\begin{array}{l}\text { H/O unprotected sex with } \\
\text { female CSW }\end{array}$} & Positive history & No (\%) & $46(76.7)$ & $37(67.3)$ & $22(73.3)$ & $11(22)$ & \multirow{3}{*}{$\mathrm{NA}^{* *}$} \\
\hline & \multirow{2}{*}{ Frequency of exposures per week } & Range & $1-3$ & $1-3$ & $1-3$ & $1-2$ & \\
\hline & & Mean \pm SD & $1.5 \pm 0.7$ & $1.6 \pm 0.6$ & $1.5 \pm 0.7$ & $1.1 \pm 0.3$ & \\
\hline & \multirow{2}{*}{ No. of partners* } & Range & $2-5$ & $2-5$ & $1-4$ & $1-2$ & \multirow{2}{*}{$\mathrm{NA}^{* *}$} \\
\hline & & Mean \pm SD & $3.1 \pm 0.9$ & $2.9 \pm 0.9$ & $2.9 \pm 0.8$ & $1.4 \pm 0.5$ & \\
\hline \multirow{3}{*}{$\begin{array}{l}\text { Consumption of alcoholic } \\
\text { drinks }\end{array}$} & Positive history & No (\%) & $55(91.7)$ & $18(31.0)$ & $28(93.3)$ & $13(26)$ & $9(22.5)$ \\
\hline & \multirow{2}{*}{ Frequency of sessions per week } & Range & $4-9$ & $1-6$ & $2-8$ & $1-2$ & $1-4$ \\
\hline & & Mean \pm SD & $6.5 \pm 1.3$ & $3.7 \pm 1.6$ & $5.3 \pm 2.1$ & $1.5 \pm 0.5$ & $1.9 \pm 1.0$ \\
\hline BMI & & Mean \pm SD & $21.6 \pm 2.1$ & $22.0 \pm 1.4$ & $21.7 \pm 1.8$ & $22.2 \pm 1.7$ & $21.4 \pm 1.0$ \\
\hline Serum albumin $(\mathrm{gm} / \mathrm{dl})$ & & Mean \pm SD & $4.1 \pm 0.4$ & $4.3 \pm 0.4$ & $4.2 \pm 0.4$ & $4.3 \pm 0.3$ & $4.1 \pm 0.2$ \\
\hline
\end{tabular}

${ }^{*}$ Calculated for those donors with positive history; ${ }^{* *}$ Not applicable. Note: Sgr I to V indicate Subgroups I to V; Fe pos and Fe neg indicate positive and negative history of oral iron consumption.

(b)

\begin{tabular}{|c|c|c|c|c|c|}
\hline \multirow{2}{*}{\multicolumn{3}{|c|}{ Baseline variables }} & \multicolumn{3}{|c|}{$P$ value } \\
\hline & & & \multirow[t]{2}{*}{ Over all } & \multirow[t]{2}{*}{ Sgr I vs Sgr II } & \multirow{2}{*}{ Sgr III vs Sgr IV } \\
\hline \multirow{4}{*}{ Blood donation frequency } & $\leq 6$ weeks & No (\%) & & & \\
\hline & $>6$ weeks $-<3$ months & No (\%) & & $<0.001^{\star *}$ & $<0.001^{\star *}$ \\
\hline & $\geq 3$ months & No (\%) & & & \\
\hline & Positive history & No (\%) & $<0.001$ & 0.12 & $<0.001$ \\
\hline \multirow[t]{2}{*}{$\mathrm{H} / \mathrm{O}$ unprotected sex with female CSW } & Frequency of exposures per week ${ }^{*}$ & Mean \pm SD & 0.1 & 0.31 & 0.06 \\
\hline & No. of partners* & Mean \pm SD & $<0.001$ & 0.32 & $<0.001$ \\
\hline \multirow{2}{*}{ Consumption of alcoholic drinks } & Positive history & No (\%) & $<0.001$ & $<0.001$ & $<0.001$ \\
\hline & Frequency of sessions per week & Mean \pm SD & $<0.001$ & $<0.001$ & $<0.001$ \\
\hline BMI & & Mean \pm SD & 0.22 & 0.99 & 0.99 \\
\hline Serum albumin (gm/dl) & & Mean \pm SD & 0.02 & 0.02 & 0.99 \\
\hline
\end{tabular}

${ }^{*}$ Calculated for those donors with positive history; ${ }^{*}$ Comparison by $\chi^{2}$ test for trend. Note: (i) Sgr I to IV indicate Subgroups of blood donors I to IV. (ii) Data not included in the above table: The BMI and serum albumin levels in subgroups I, II, III and IV were individually comparable to subgroup V (non-donor community controls) ( $\mathrm{p}=0.69,0.99,0.99$ and 0.32 respectively for BMI and $0.9,0.22,0.99$ and 0.99 for serum albumin level). 